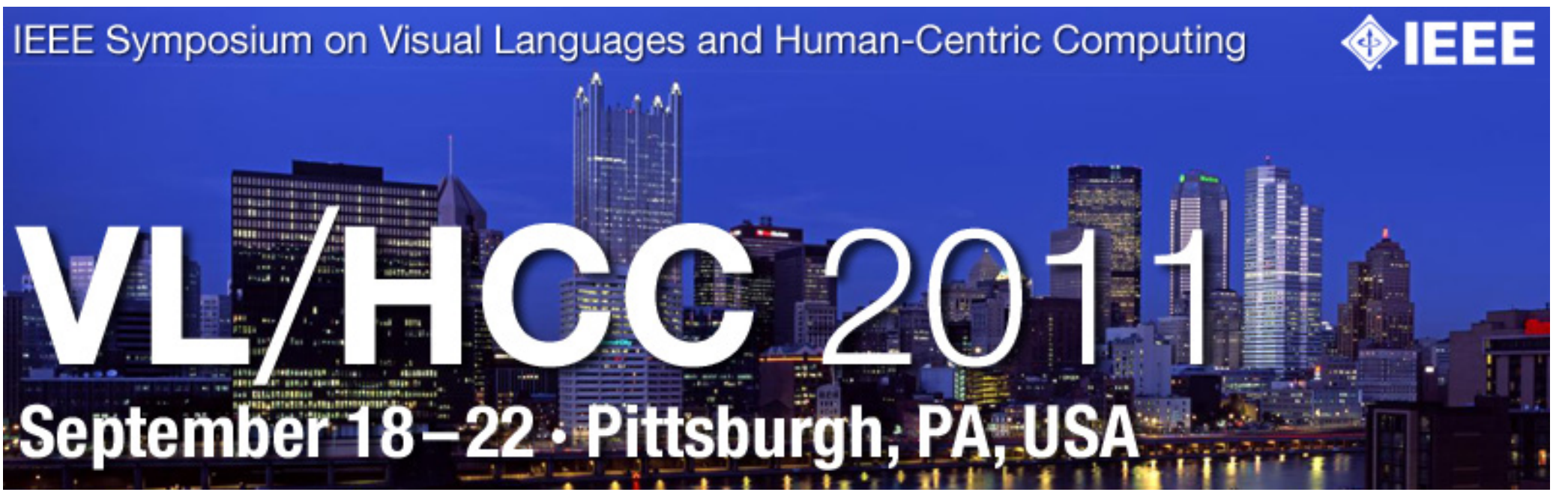

\title{
Program at a Glance
}

\begin{tabular}{|c|c|c|c|c|c|}
\hline & $\begin{array}{l}\text { Sunday } \\
9 / 18\end{array}$ & $\begin{array}{l}\text { Monday } \\
9 / 19\end{array}$ & $\begin{array}{l}\text { Tuesday } \\
\text { 9/20 }\end{array}$ & $\begin{array}{l}\text { Wednesday } \\
9 / 21\end{array}$ & $\begin{array}{l}\text { Thursday } \\
\text { 9/22 }\end{array}$ \\
\hline $\begin{array}{l}\text { Early } \\
\text { Morning }\end{array}$ & \multirow{4}{*}{$\begin{array}{l}\text { Graduate } \\
\text { Consortium }\end{array}$} & $\begin{array}{l}\text { Successful } \\
\text { Visual End- } \\
\text { User } \\
\text { Programming } \\
\text { Systems }\end{array}$ & $\begin{array}{c}\text { Keynote - } \\
\text { Jeanette Wing }\end{array}$ & $\begin{array}{c}\text { Keynote - } \\
\text { Brian H. } \\
\text { Powell }\end{array}$ & \multirow{4}{*}{$\begin{array}{c}\text { EUSES } \\
\text { Workshop }\end{array}$} \\
\hline $\begin{array}{l}\text { Late } \\
\text { Morning }\end{array}$ & & $\begin{array}{l}\text { Visual Domain- } \\
\text { Specific } \\
\text { Languages }\end{array}$ & $\begin{array}{c}\text { Visual } \\
\text { Languages \& } \\
\text { Theory }\end{array}$ & $\begin{array}{c}\text { Software } \\
\text { Development } \\
\text { and Usability }\end{array}$ & \\
\hline $\begin{array}{l}\text { Early } \\
\text { Afternoon }\end{array}$ & & $\begin{array}{l}\text { End-User } \\
\text { Programming }\end{array}$ & $\begin{array}{l}\text { Debugging \& } \\
\text { Program } \\
\text { Understanding }\end{array}$ & Models & \\
\hline $\begin{array}{l}\text { Late } \\
\text { Afternoon }\end{array}$ & & Tools & $\begin{array}{c}\text { Program } \\
\text { Understanding }\end{array}$ & $\begin{array}{l}\text { Diagrams and } \\
\text { Visualization }\end{array}$ & \\
\hline Evening & $\begin{array}{l}\text { Opening } \\
\text { Reception }\end{array}$ & $\begin{array}{c}\text { Posters \& } \\
\text { Demos Dinner } \\
\text { Reception }\end{array}$ & $\begin{array}{c}\text { Grand } \\
\text { Reception at } \\
\text { National Aviary }\end{array}$ & & \\
\hline
\end{tabular}

\section{Thank You to Our Symposium Sponsors}

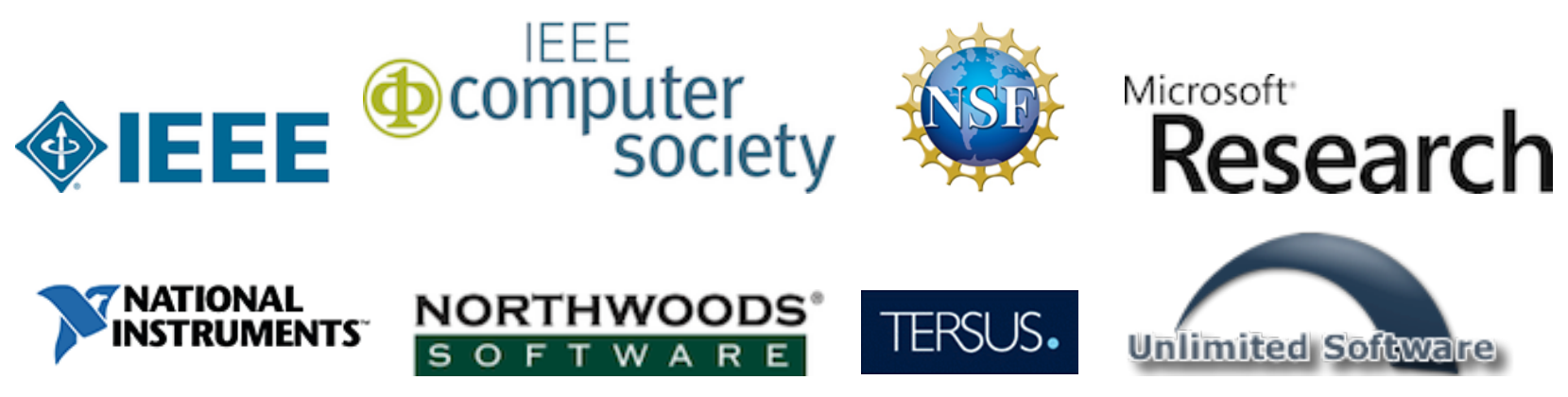




\section{Sunday, September 18}

Starts at

9:15
GRADUATE CONSORTIUM: EXPANDING END USER CONTROL IN SOCIOTECHNICAL SYSTEMS

Carnegie Mellon University

19:30-22:00 Opening Reception with Light Refreshments

Sheraton Station Square, Fountainview Room

All main conference sessions in Sheraton Station Square, Grand Station Ballroom $3 \& 4$.

\section{Monday, September 19}

\section{8:00- 9:00 Registration and Continental Breakfast}

9:00- 9:10 Conference Opening

Brad Myers · Carnegie Mellon University, USA

9:10-10:30 Successful Visual and End-User Programming Systems · PANEL

MODERATOR Brad Myers · Carnegie Mellon University, USA

PANELISTS Ofer Brandes - Tersus Visual Programming Platform

CEO, Tersus Software

Allen Cypher - CoScripter

Research Scientist, IBM Research - Almaden

Andrew P. Dove - LabVIEW

Principal Architect, National Instruments Corporation

Peter Lucas - CPoF and Visage

Principal, MAYA Design

Alexander Repenning - AgentSheets

CTO, AgentSheets and Professor, University of Colorado Boulder

Walter van Roggen - Sanscript and GoDiagram

Vice President, Northwoods Software

11:00-12:30 VISUAL DOMAIN-SPECIFIC LANGUAGES

SESSION CHAIR Paolo Bottoni · Sapienza - Università di Roma, Italy

Obstacles and opportunities with using visual and domain-specific languages in scientific programming - PAPER

Michael Jones · Oregon State University, USA

Christopher Scaffidi · Oregon State University, USA

Quick fix generation for DSMLs · PAPER 
Ábel Hegedüs - Budapest University of Technology and Economics, Hungary Ákos Horváth - Budapest University of Technology and Economics, Hungary Istvan Rath - Budapest University of Technology and Economics, Hungary Moises C. Branco · University of Waterloo, Canada Daniel Varro · University of Waterloo, Canada

Ruru: A spatial and interactive visual programming language for novice robot programming · PAPER

James Diprose $\cdot$ University of Auckland, New Zealand

Bruce Macdonald - University of Auckland, New Zealand

John Hosking · University of Auckland, New Zealand

14:30-16:00 END-USER PROGRAMMING

SESSION CHAIR Mary Beth Rosson · Pennsylvania State University, USA

An Exploration of Design Opportunities for "Gardening" End-User

Programmers' Ideas ·PAPER

Jill Cao · Oregon State University, USA

Scott D. Fleming · Oregon State University, USA

Margaret Burnett · Oregon State University, USA

Scenario Markup Language for Authoring Behavioral Driver Studies in 3D

Virtual Worlds · SHORT PAPER

Kugamoorthy Gajananan - Graduate University for Advanced Studies, Japan

Arturo Nakasone · Graduate University for Advanced Studies, Japan

Helmut Prendinger · Graduate University for Advanced Studies, Japan

Marc Miska - Queensland University of Technology, Australia

Mini-Crowdsourcing End-User Assessment of Intelligent Assistants: A CostBenefit Study · PAPER

Amber Shinsel - Oregon State University, USA

Todd Kulesza · Oregon State University, USA

Margaret Burnett · Oregon State University, USA

William Curran · Oregon State University, USA

Alex Groce · Oregon State University, USA

Simone Stumpf · City University London, UK

Weng-Keen Wong · Oregon State University, USA

An Investigation of Non-Programmers' Performance with Tools to Support Output Localization · SHORT PAPER

Paul Gross - Washington University in St. Louis, USA

Jennifer Yang · University of Washington, USA

Caitlin Kelleher · Washington University in St. Louis, USA

16:30-17:15 TOOLS

SESSION CHAIR Alexander Repenning · AgentSheets, University of Colorado Boulder, USA

Automatic Diagram Layout Support for the Marama Meta-toolset - SHORT PAPER Pei Shan Yap · University of Auckland, New Zealand 
John Hooking · University of Auckland, New Zealand

John Grundy · Swinburne University of Technology, Australia

Examining Interaction with General-Purpose Object Recognition in LEGO OASIS · SHORT PAPER

Ryder Ziola · University of Washington, USA

Shweta Grampurohit · University of Washington, USA

Nate Landes · University of Washington, USA

James Fogarty · University of Washington, USA

Beverly Harrison · Intel Labs Seattle, USA

History Repeats Itself More Easily When You Log It: Versioning for

Mashups - SHORT PAPER

Sandeep Kuttal · University of Nebraska - Lincoln, USA

Anita Sarma - University of Nebraska - Lincoln, USA

Gregg Rothermel · University of Nebraska - Lincoln, USA

17:15-18:00 Overview of All Posters and Demonstrations

19:00-22:00

POSTERS AND DEMONSTRATIONS DINNER RECEPTION

Reception at Carnegie Mellon University

4 


\section{Tuesday, September 20}

\section{8:30- 9:00 Registration and Continental Breakfast}

9:00- 10:30 Computational Thinking - KEYNOTE

Jeanette M. Wing · Carnegie Mellon University, USA

11:00 - 12:30 VISUAL LANGUAGES AND THEORY

SESSION CHAIR Mark Minas · Universität der Bundeswehr München, Germany

SketchSet: Creating Euler Diagrams using Pen or Mouse - PAPER

Mengdi Wang · University of Auckland, New Zealand

Beryl Plimmer · University of Auckland, New Zealand

Paul Schmieder - University of Auckland, New Zealand

Gem Stapleton · University of Brighton, UK

Peter Rodgers · University of Kent, UK

Aidan Delaney · University of Brighton, UK

Identifying Attachment Areas on Sketched Symbols · SHORT PAPER

Gennaro Costagliola · University of Salerno, Italy

Mattia De Rosa - University of Salerno, Italy

Vittorio Fuccella · University of Salerno, Italy

Deriving Sound Inference Rules for Concept Diagrams · PAPER

Peter Chapman · University of Brighton, UK

Gem Stapleton · University of Brighton, UK

John Howse · University of Brighton, UK

lan Oliver · Nokia Research, Finland

Policy Specifications with Timed Spider Diagrams · SHORT PAPER

Paolo Bottoni · Sapienza - Università di Roma, Italy

Andrew Fish · University of Brighton, UK

14:30-16:00 DEBUGGING AND PROGRAM UNDERSTANDING

SESSION CHAIR Martin Erwig · Oregon State University, USA

Coping with Duplicate Bug Reports in Free/Open Source Software

Projects · PAPER

Jennifer Davidson · Oregon State University, USA

Nitin Mohan - Oregon State University, USA

Carlos Jensen · Oregon State University, USA

Modeling Programmer Navigation: A head-to-head empirical evaluation of predictive models · PAPER

David Piorkowski · Oregon State University, USA

Scott D. Fleming · Oregon State University, USA 
Christopher Scaffidi · Oregon State University, USA

Liza John · Carnegie Mellon University, USA

Christopher Bogart · Oregon State University, USA

Bonnie E. John - IBM Research - T.J. Watson and Carnegie Mellon University, USA

Margaret Burnett · Oregon State University, USA

Rachel Bellamy · IBM Research - T.J. Watson, USA

Visualizing Call Graphs · PAPER

Thomas LaToza $\cdot$ Carnegie Mellon University, USA

Brad Myers · Carnegie Mellon University, USA

16:30-18:00 PROGRAM UNDERSTANDING

SESSION CHAIR Margaret Burnett · Oregon State University, USA

\section{Enabling Program Comprehension through a Visual Object-focused \\ Development Environment · PAPER}

Fernando Olivero · University of Lugano, Switzerland

Michele Lanza · University of Lugano, Switzerland

Marco D'Ambros · University of Lugano, Switzerland

Romain Robbes · University of Chile, Chile

On the Impact of Layout Quality to Understanding UML Diagrams - PAPER Harald Störrle · Technical University of Denmark, Denmark

\#ifdef Confirmed Harmful: Promoting Understandable Software Variation · PAPER

Duc Le $\cdot$ Oregon State University, USA

Eric Walkingshaw · Oregon State University, USA

Martin Erwig · Oregon State University, USA

\section{9:00-23:00 Grand Reception at the National Aviary}




\section{Wednesday, September 21}

\section{8:30- 9:00 Registration and Continental Breakfast}

9:00-10:30 The Keys to Solving the World's Top Engineering Challenges - KEYNOTE Brian H. Powell · National Instruments Corporation, USA

11:00-12:30 SOFTWARE DEVELOPMENT AND USABILITY

SESSION CHAIR John Grundy · Swinburne University of Technology, Australia

Improving Usability of Interactive Graphics Specification and Implementation with Picking Views and Inverse Transformations · PAPER

Stéphane Conversy · ENAC-LII, IRIT-ICS and Université de Toulouse, France

Why do Programmers Make Security Errors? · SHORT PAPER Jing Xie - University of North Carolina at Charlotte, USA Heather Lipford - University of North Carolina at Charlotte, USA Bei-Tseng Chu · University of North Carolina at Charlotte, USA

Restructuring Software with Gestures · PAPER

Emerson Murphy-Hill · North Carolina State University, USA

Moin Ayazifar · North Carolina State University, USA

Andrew Black · Portland State University, USA

The Role of Conceptual Knowledge in API Usability - SHORT PAPER

Andrew Ko - University of Washington, USA

Yann Riche $\cdot$ Microsoft Corporation, USA

14:30-16:00 MODELS

SESSION CHAIR Gem Stapleton • University of Brighton, UK

Embedding and Evolution of Spreadsheet Models in Spreadsheet

Systems - PAPER

Jácome Cunha - Universidade do Minho, Portugal

Jorge Mendes · Universidade do Minho, Portugal

João Saraiva · Universidade do Minho, Portugal

João Paulo Fernandes - Universidade do Minho and Universidade do Porto, Portugal

Allowing End-users to Participate within Model-Driven Development Approaches ·SHORT PAPER

Francisca Pérez · Universitat Politècnica de València, Spain

Pedro Valderas · Universitat Politècnica de València, Spain

Joan Fons · Universitat Politècnica de València, Spain

Future Trace: Making Programming more Conversational · SHORT PAPER 
Alexander Repenning · AgentSheets and University of Colorado Boulder, USA

Expressing Model Constraints Visually with VMQL · PAPER

Harald Störrle · Technical University of Denmark, Denmark

16:30-17:45 DIAGRAMS AND VISUALIZATION

SESSION CHAIR Andrew Fish • University of Brighton, UK

Progressor: Personalized visual access to programming

problems · SHORT PAPER

Fedor Bakalov · Friedrich Schiller University of Jena, Germany

I-Han Hsiao • University of Pittsburgh, USA

Peter Brusilovsky · University of Pittsburgh, USA

Birgitta König-Ries · Friedrich Schiller University of Jena, Germany

Automatically Drawing Euler Diagrams with Circles and Ellipses - SHORT PAPER Gem Stapleton · University of Brighton, UK

Peter Rodgers · University of Kent, UK

Aesthetic of Angular Resolution for Node-Link Diagrams: Validation and Algorithm · SHORT PAPER

Weidong Huang - University of Technology and CSIRO ICT Centre, Australia Maolin Huang · University of Technology, Australia

Chun-Cheng Lin · National Chiao Tung University, Taiwan

Evaluating Visual and Statistical Exploration of Scientific Literature

Networks · PAPER

Robert Gove · University of Maryland, USA

Cody Dunne - University of Maryland, USA

Ben Shneiderman · University of Maryland, USA

Judith Klavans · University of Maryland, USA

Bonnie Dorr · University of Maryland, USA

17:45-18:00 Conference Closing and VL/HCC 2012 Introduction

Brad Myers · Carnegie Mellon University, USA

Gennaro Costagliola $\cdot$ University of Salerno, Italy

\section{Thursday, September 22}

All day Post-conference EUSES Workshop 


\section{VL/HCC}

\section{Posters and Demonstrations Dinner Reception}

Monday, September 19, 2011, 7:00pm

Location: Newell-Simon Hall Atrium - Carnegie Mellon University

A shuttle bus will run continuously from $6: 15 \mathrm{pm}$ until 10:00pm between the Sheraton Station Square and the Posters and Demonstrations Dinner Reception

location, which is the Atrium of Newell-Simon Hall (NSH) on the Carnegie Mellon University Campus. If you want to drive, you can park for free at CMU in the Morewood Parking Lot, which is approximately at 4900 Forbes Avenue, 15213. The included campus map shows the parking lot and NSH.

\section{Atrium Map}

\section{Corporate Sponsor Demos Demos}

Entrance

Full

Paper

Demos

\section{Doctoral Consortium Posters}

\section{Posters}




\section{VL/HCC}

Presentations are ordered as listed below and arranged clockwise in the atrium starting on your left as you enter through the doors.

\section{Corporate Sponsor Demos}

Tersus Visual Programming Platform

Ofer Brandes · Tersus Software, Israel

Debugger Canvas

Rob DeLine $\cdot$ Microsoft Research, USA

Rapid Prototyping of Mobile Applications for Augmented Reality Interactions

Michele Di Capua · Unlimited Software, Italy

Gennaro Costagliola · University of Salerno, Italy

Mattia De Rosa · University of Salerno, Italy

Vittorio Fuccella · University of Salerno, Italy

Rapid Deployment of Graphical and Textual Code to Real-Time Targets

Andrew P. Dove · National Instruments, USA

\section{Other Corporate Demos}

GameSalad: Bringing Game Creation to Everyone

Michael Agustin · GameSalad, USA

\section{Demos}

Visual Programming and Music Score Generation with OpenMusic Jean Bresson - STMS: IRCAM-CNRS-UPMC, France

Carlos Agon · STMS: IRCAM-CNRS-UPMC, France

Breviz: Spreadsheet Visualization and Quality Analysis

Felienne Hermans · Delft University of Technology, Netherlands

Scripting a Radically-Distributed World

Peter Lucas - MAYA Design, USA

Jeff Senn · MAYA Design, USA

Magesh Balasubramana - MAYA Design, USA

Stuart Roth - MAYA Design, USA

Steve Spencer - MAYA Design, USA 
Inflo: End-user Visual Computation Supporting Sharing \& Reuse

Jonathan Lung · University of Toronto, Canada

Steve Easterbrook · University of Toronto, Canada

\section{Active Code Completion}

Cyrus Omar · Carnegie Mellon University, USA

YoungSeok Yoon · Carnegie Mellon University, USA

Thomas D. LaToza · Carnegie Mellon University, USA

Brad A. Myers · Carnegie Mellon University, USA

\section{Conversational Programming in Action}

Alexander Repenning · AgentSheets and University of Colorado Boulder, USA

Programming in Pictures within Filmification Modeling Environment

Yutaka Watanobe · University of Aizu, Japan

Rentaro Yoshioka · University of Aizu, Japan

Nikolay Mirenkov · University of Aizu, Japan

\section{Full Paper Demos}

\section{HaExcel: A Model-based Spreadsheet Evolution System}

Jácome Cunha · Universidade do Minho, Portugal

João Paulo Fernandes · Universidade do Minho and Universidade do Porto, Portugal

Jorge Mendes · Universidade do Minho, Portugal

João Saraiva · Universidade do Minho, Portugal

Coping with Duplicate Bug Reports in Free/Open Source Software Projects Jennifer Davidson · Oregon State University, USA

Nitin Mohan · Oregon State University, USA

Carlos Jensen · Oregon State University, USA

\section{Ruru}

James Diprose · University of Auckland, New Zealand

Evaluating Visual and Statistical Exploration of Scientific Literature Networks Robert Gove · University of Maryland, USA

\section{Quick fix generation for DSMLs}

Ábel Hegedüs - Budapest University of Technology and Economics, Hungary

Ákos Horváth · Budapest University of Technology and Economics, Hungary

Istvan Rath - Budapest University of Technology and Economics, Hungary

Moises C. Branco · University of Waterloo, Canada

Daniel Varro · University of Waterloo, Canada

\section{Progressor}

I-Han Hsiao · University of Pittsburgh, USA 
Pipes Plumber

Sandeep Kuttal · University of Nebraska - Lincoln, USA

\section{Visualizing Call Graphs}

Thomas D. LaToza · Carnegie Mellon University, USA

Gaucho

Fernando Olivero · University of Lugano, Switzerland

\section{WYSIWYT/ML}

Amber Shinsel · Oregon State University, USA

\section{SketchSet: Creating Euler Diagrams using Pen or Mouse}

Mengdi Wang · University of Auckland, New Zealand

Beryl Plimmer · University of Auckland, New Zealand

Paul Schmieder · University of Auckland, New Zealand

Gem Stapleton · University of Brighton, UK

Peter Rodgers · University of Kent, UK

Aidan Delaney · University of Brighton, UK

\section{Posters}

\section{Can Learning Acquisition Be Computed?}

Vicki Bennett - University of Colorado Boulder, USA

Kyu Han Koh · University of Colorado Boulder, USA

Alexander Repenning · AgentSheets and University of Colorado Boulder, USA

REST based Service Composition: Exemplified in a Care Network Scenario

Erik Grönvall · Aarhus University, Denmark

Mads Ingstrup · Aarhus University, Denmark

Morten Pløger · Aarhus University, Denmark

Morten Rasmussen · Aarhus University, Denmark

Tabular Form Editing with a Hexadecimal Grid Graph Model

Shinji Koka · Nihon University, Japan

Koichi Anada - Waseda University, Japan

Kenshi Nomaki · Nihon University, Japan

Takeo Yaku $\cdot$ Nihon University, Japan

Beyond Autocomplete: Automatic Function Definition

Kyle I. Murray - University of Rochester, USA

Jeffrey P. Bigham · University of Rochester, USA

Impure: a Visual Programming Language for the Data Age

Santiago Ortiz $\cdot$ Bestiario, Spain

Victor Pascual Cid $\cdot$ Bestario, Spain 
A Graph Grammar Model for Syntaxes of Financial Statements

Yuki Shindo · Nihon University, Japan

Koichi Anada - Waseda University, Japan

Koushi Anzai · Kanto Gakuen University, Japan

Shinji Koka - Nihon University, Japan

Row Manipulation in the Heterogenous Tabular Forms with an Octal Grid Model

Takeo Yaku · Nihon University, Japan

Koichi Anada - Waseda University, Japan

Shinji Koka · Nihon University, Japan

Yuki Shindo · Nihon University, Japan

Kensei Tsuchida $\cdot$ Toyo University, Japan

\section{Doctoral Consortium Posters}

“Gardening" End-User Programmers' Ideas

Jill Cao · Oregon State University, USA

End User Robot Programming via Visual Languages

James Diprose · University of Auckland, New Zealand

Computing Indicators of Creativity

Kyu Han Koh · University of Colorado Boulder, USA

Support for Software Variation Editing

Duc Le · Oregon State University, USA

ClassSheet-driven Spreadsheet Environments

Jorge Mendes · Universidade do Minho, Portugal

Injecting Computational Thinking into Career Explorations for Middle School Girls Heidi Webb · Pennsylvania State University, USA

Measuring Flow in Programming Education

Mark Zarb · University of Dundee, UK 


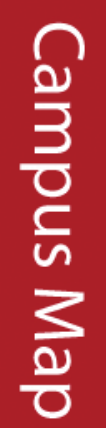

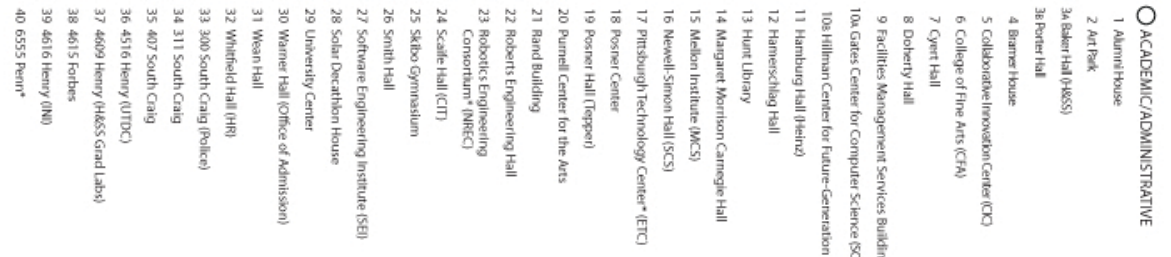
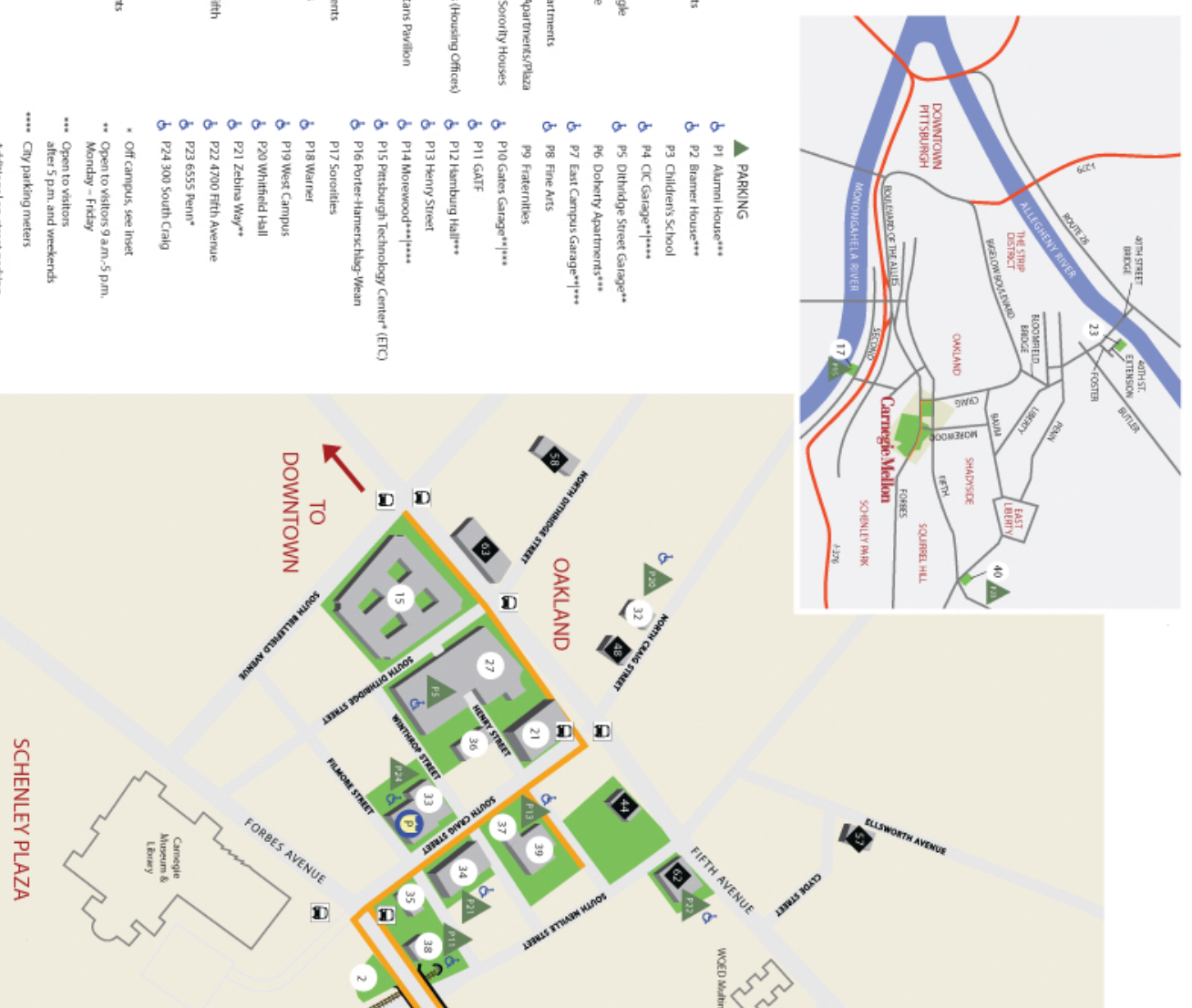

?.

产

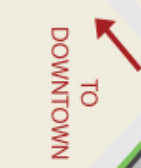

$\sin ^{\infty}$

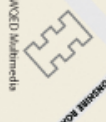

(A)

(3)

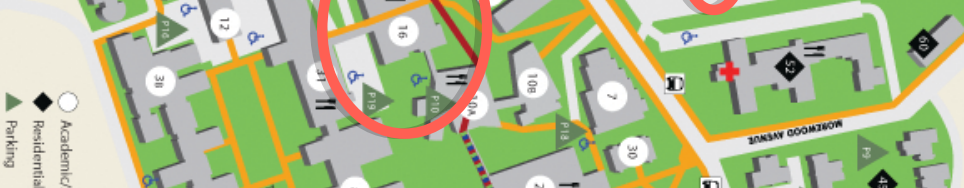

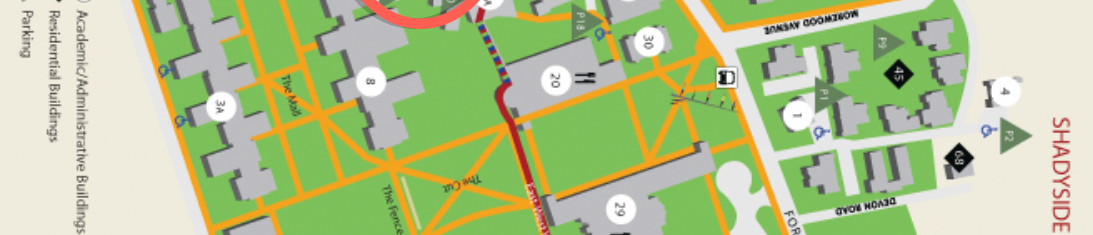

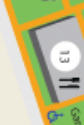

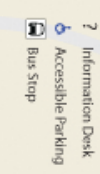

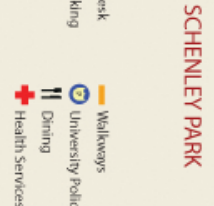

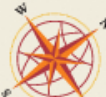

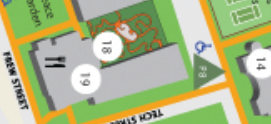

$=\left.\right|_{2=1} ^{1=1}$ 